Short Communication

\title{
Uranium Dissolution Behavior in LiCl-KCl Molten Salts
}

\author{
Sung-Jai Lee, Gha-Young Kim ${ }^{*}$ \\ Pyroprocess Technology Division, Korea Atomic Energy Research Institute, 989-111 Daedeok-daero, \\ Yuseong-gu, Daejeon, 34057, Republic of Korea \\ *E-mail: gkim@kaeri.re.kr
}

doi: $10.20964 / 2017.09 .61$

Received: 14 June 2017 / Accepted: 28 July 2017 / Published: 13 August 2017

\begin{abstract}
Uranium (U) dissolution behavior at an anode during electrorefining was investigated by employing the potentiodynamic polarization method, galvanostatic potential transient technique, AC impedance spectroscopy, and potentiostatic current transient technique. For this purpose, a U pellet of diameter 8 $\mathrm{mm}$ and length $10 \mathrm{~mm}$ was used as the working electrode. From the quantitative analyses of the polarization curve and potential transient curves, the kinetic parameters governing the $U$ dissolution reaction, such as the exchange current density and diffusivity of $\mathrm{U}$ ions in the LiCl-KCl fused salt, were determined. From the impedance spectra and anodic current transient curves obtained at various applied potentials, it was confirmed that the interfacial charge transfer for U dissolution is kinetically coupled with diffusion through the electrolyte. In addition, we found that AC impedance spectroscopy was more useful compared to the potentiostatic current transient technique in the presence of a large uncompensated ohmic potential drop.
\end{abstract}

Keywords: Pyroprocessing, Electrorefining, Uranium dissolution, Dissolution mechanism, Kinetic parameter

\section{$\underline{\text { FULL TEXT }}$}

(C) 2017 The Authors. Published by ESG (www.electrochemsci.org). This article is an open access article distributed under the terms and conditions of the Creative Commons Attribution license (http://creativecommons.org/licenses/by/4.0/). 